\title{
Efeito Retroativo e Multimodalidade no ENEJM: análise de questões de inglês e espanhol
}

\author{
Washback and Multimodality in the Brazilian National Exam of \\ Upper SECONDARy Education (ENEM): ANALySES of ITEMS \\ IN ENGLISH AND SPANISH
}

Larisse Lázaro Santos Pinheiro*
Gladys Quevedo-Camargo**

Resumo: O presente artigo discute o efeito retroativo potencial do Exame Nacional do Ensino Médio (ENEM) na sala de aula de línguas estrangeiras a partir da análise de algumas questões de língua inglesa e língua espanhola utilizadas nas edições de 2013, 2014 e 2015 do ENEM. Esta discussão tem por base os trabalhos de Alderson e Wall (1993), Bachman e Palmer (1996), Scaramucci (2004) e Quevedo-Camargo (2014), assim como a Teoria da Multimodalidade, baseada nos pressupostos teóricos de Kress e Van Leuween (1996) e Baldry e Thibault (2006), que definem o texto multimodal como aquele que tem seus significados realizados por várias semioses, como linguagem, gesto, movimento, imagens, letras, cores, dentre outros. $\mathrm{O}$ artigo se configura como uma pesquisa de natureza qualitativa em que se privilegia a interpretação e reinterpretação de dados, e caracteriza-se como um estudo de caso interpretativista. As análises das questões em inglês e espanhol levam-nos a refletir sobre os elementos que compõem o ensino de leitura de

\footnotetext{
* Mestranda em Linguística Aplicada pelo PGLA da Universidade de Brasília - UNB. Pesquisadora da área de Multimodalidade e Ensino de Língua Estrangeira. Contato: larisselazaro@hotmail.com.

** Pós-doutorado com pesquisa na área de avaliação na Universidade Estadual de Campinas - UNICAMP (2013). Docente da Universidade de Brasília. Contato: gladys@unb.br.
} 
textos verbais e não verbais, bem como sobre a importância de a escola desenvolver multiletramentos.

Palavras-chave: Efeito retroativo. ENEM. Multimodalidade.

Abstract: This study aims at discussing the potential washback of the Brazilian National Exam of Upper Secondary Education (ENEM) by analyzing some of the items in English and Spanish used in the 2013, 2014 and 2015 exam editions. This discussion is based on the studies by Alderson e Wall (1993), Bachman \& Palmer (1996), Scaramucci (2004) and Quevedo-Camargo (2014) as well as on the Multimodality Theory by Kress \& Van Leuween (1996) and Baldry \& Thibault (2006), who define a multimodal text as the one whose meanings are realized by several types of semiosis such as language, gesture, movement, image, letter, colours, among others. This is a qualitative study which favours interpretation and reinterpretation of data. The analyses of the items in English and Spanish lead us to reflect upon the elements that constitute the teaching of reading of both verbal and non-verbal texts, and upon the importance of developing multiliteracies at school.

Keywords: Washback. ENEM. Multimodality.

\section{Introdução}

Os processos avaliativos utilizados em ambientes escolares, particularmente naqueles em que as línguas são trabalhadas, são caracterizados por distintas metodologias e motivados a partir de vários objetivos. Por avaliarem especificamente os conteúdos curriculares e habilidades trabalhadas em classe, as várias modalidades de avaliações são fundamentais para o desenvolvimento constante do trabalho pedagógico, tendo em vista a aprendizagem do aluno.

No entanto, a avaliação ao qual este artigo se refere é a realizada em larga escala, externa à escola, que tem o propósito de produzir informações que podem vir a embasar deliberações políticas e pedagógicas com o intuito de favorecer os sistemas educacionais.

Nesse sentido, este artigo investiga o Exame Nacional do Ensino Médio (ENEM), buscando estabelecer uma discussão acerca do possível impacto 
positivo fora e dentro da sala de aula em alunos e professores, levando em consideração a Teoria da Multimodalidade. Por meio da análise de algumas questões de Língua Estrangeira (LE) dos ENEM 2013, 2014 e 2015, este artigo também verifica de que maneira esse exame explora a compreensão textual em suas questões envolvendo os textos multimodais.

Desse modo, com o propósito de criar ambiente favorável à fundamentação, este artigo está organizado da seguinte forma: em um primeiro momento, apresentamos o contexto em que o ENEM se encontra atualmente, a justificativa para o seu estudo e alguns aspectos conceituais de avaliação como o efeito retroativo da avaliação em línguas estrangeiras (ALDERSON; WALL, 1993; BACHMAN; PALMER, 1996; SCARAMUCCI, 2004; QUEVEDO-CAMARGO, 2014) e construto (BACHMAN, 1990; BROWN, 2004; SCARAMUCCI, 2011). Em seguida, apresentamos o arcabouço teórico em que se sustentam as análises, constituído pela Teoria da Multimodalidade (BALDRY; THIBAULT, 2006; KRESS; VAN LEEUWEN, 2006). Nessa perspectiva, discutimos o conceito e o construto do texto multimodal, que será o foco de análise deste artigo. $\mathrm{Na}$ sequência, analisamos quatro das questões propostas nos anos 2013, 2014 e 2015, a partir da metodologia de pesquisa adotada, e finalizamos com reflexões sobre o texto multimodal no ENEM, seu efeito retroativo potencial, e a importância do multiletramento nesse contexto.

Para início da reflexão, consideramos importante abordar alguns conceitos de avaliação, como efeito retroativo e construto, contextualizando-os com o ENEM, aspectos sobre os quais discorremos na seção seguinte.

\section{O Exame Nacional do Ensino Médio (ENEM)}

O ENEM foi implantado no sistema educacional brasileiro em 1998 e tinha como função primordial avaliar as competências básicas de alunos oriundos do Ensino Médio (EM), caracterizava-se como um exame alternativo ou complementar dos vestibulares das universidades brasileiras. Em 2009, houve uma ampliação das funções atribuídas a ele, e tal reforma determinou uma mudança nas concepções de educação, contextualizada e interdisciplinar, com eixos norteadores, conforme os Parâmetros Curriculares 
Nacionais (PCN) (BRASIL, 2006), em que se valoriza o desenvolvimento de competências e habilidades.

Dessa forma, o exame é dividido em cinco áreas do conhecimento: Ciências Naturais e suas Tecnologias; Linguagem, Códigos e suas Tecnologias; Matemática e suas Tecnologias; Ciências Humanas e suas Tecnologias e Redação. São 180 itens aplicados em dois dias, mantendo-se a obrigatoriedade da redação.

Atualmente, o ENEM constitui-se em um exame de grande relevância por ser o processo seletivo para ingresso em diversas instituições públicas do Ensino Superior, bem como o processo seletivo para concessão de bolsas e financiamento de cursos de graduação em instituições particulares. Dessa forma, a dimensão desse exame se dá principalmente devido ao grande número de estudantes que desejam cursar o ensino superior.

Ainda há poucos dados a respeito do impacto do ENEM no sistema educacional brasileiro. No entanto, os dados obtidos através desse exame podem servir de incentivo para a implementação de políticas públicas e, principalmente, servir também como parâmetro para o aperfeiçoamento dos currículos do EM à medida que suas questões demandem conhecimentos e processos cognitivos que contribuam para o desenvolvimento intelectual e linguístico dos alunos. Além disso, alguns aspectos suscitados pelo ENEM podem provocar reflexões dentro e fora da sala de aula, levando o professor a incorporar novas práticas de ensino e aprendizagem.

Portanto, a escolha desse exame para análise deu-se devido ao fato do seu grande potencial para impactar todo o sistema educacional. A próxima seção aprofunda essa discussão.

\subsection{Sobre o efeito retroativo do ENEM}

No campo educacional, o ENEM tem um potencial transformador, e pode influenciar o currículo, tanto em relação ao conteúdo quanto em relação aos seus pressupostos e suas abordagens. Esse exame pode levar a decisões de alto impacto para toda a sociedade.

Falar de impacto na área de avaliação é o mesmo que falar de efeito retroativo, denominado também como washback effect ou backwash effect (QUEVEDO-CAMARGO, 2014). 
No entanto, há muitas controvérsias relacionadas às considerações terminológicas e conceituais desse termo. Para Alderson e Wall (1993), o efeito retroativo é o mesmo que os efeitos dos testes na aprendizagem, restritos apenas ao que ocorre na sala de aula, enquanto impacto seria o efeito que os testes têm na sociedade. Porém, para outros autores, como Scaramucci (2002) e Cheng (2004), efeito retroativo seria sinônimo de impacto. Nessa perspectiva, com base nos pressupostos teóricos de Scaramucci (2004), neste artigo o termo "efeito retroativo" faz menção ao impacto de uma avaliação de larga escala no ensino-aprendizagem. Segundo Cheng (2004, p. 147), "há evidências convincentes para sugerir que os exames, especialmente os de alta relevância, têm forte efeito retroativo no ensino e na aprendizagem dentro de diferentes contextos educacionais".

Esse fenômeno é muito importante e complexo. Scaramucci (2004, p. 204) afirma que

o conceito de efeito retroativo pressupõe compreender os mecanismos operantes na relação entre ensino, aprendizagem e avaliação que, de acordo Bachman e Palmer (1996), é muito mais complexa do que apenas a influência de um teste no ensino e na aprendizagem.

Por isso, a importância dos estudos sobre efeito retroativo.

Até o início dos anos 1990, a visão determinista predominava em relação ao efeito retroativo (ALDERSON; WALL, 1993). Havia a crença de que testes suscitavam, necessariamente, consequências negativas no ensino e na aprendizagem. Entretanto, houve uma desmistificação do efeito retroativo negativo com a publicação do artigo de Alderson e Wall, em 1993, intitulado Does washback exist?, no qual os autores afirmam que tal efeito também pode ser positivo. Dessa forma, percebeu-se a necessidade de novas pesquisas baseadas em estudos científicos.

Nesse sentido, Quevedo-Camargo (2014, p. 82) certifica que

Começava, então, uma nova fase nas investigações sobre o efeito retroativo provocado por avaliações (exames ou testes), principalmente as de alta relevância, abarcando não somente esse fenômeno no âmbito escolar, mas também no âmbito social, ético e político e contextos de ensino aprendizagem de línguas. 
Portanto, o efeito retroativo passa a ser reconhecido como um fenômeno que depende de diversas variáveis e pode ou não ocorrer, negativa ou positivamente. Nesse sentido, há alguns aspectos do ensino e da aprendizagem que podem ser influenciados pelo teste como: os participantes, o processo e o produto, conhecidos como Tricotomia de Hughes (HUGHES, 2003); e o programa e o aluno (BAILEY, 1996 apud SCARAMUCCI, 2004). Há, também, outros aspectos que podem contribuir para que haja efeito retroativo, como a construção dos itens do teste, o prestígio do teste diante dos candidatos e da sociedade, questões pessoais, como nervosismo ou experiências prévias com exames, o microcontexto, is to é, a sala de aula ou o ambiente em que o teste é aplicado, e o macrocontexto, que pode ser a escola ou a sociedade como um todo.

O ENEM tem sido um valioso instrumento da política de implementação da reforma do ensino médio, enfatizando a avaliação do perfil de saída dos egressos. Conforme explicita a Figura 1, o impacto do ENEM pode ser percebido:

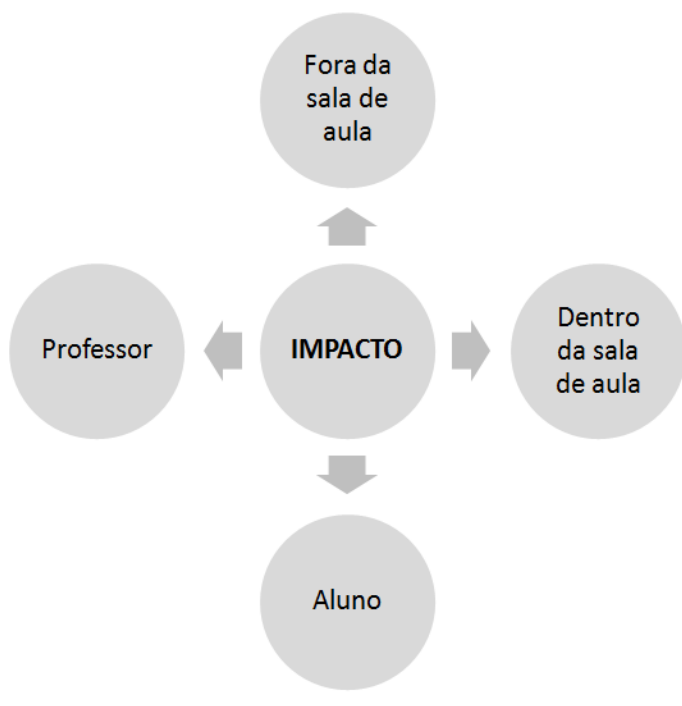

Fonte: As autoras.

Figura 1: Esquema do impacto no ENEM 
O impacto é evidente fora da sala de aula, com o surgimento de cursos preparatórios, adaptação de livros por parte das editoras, maior exposição do exame na mídia e, principalmente, maior aceitação social. Menos evidente, mas não menos importante, o impacto do ENEM dentro da sala de aula pode ser percebido pela presença de gêneros discursivos diferentes dos que são normalmente trabalhados pelo professor, de novos materiais com alterações didáticas e maior ênfase nos temas abordados em provas anteriores do ENEM.

Com relação ao impacto nos alunos, destaca-se que eles passaram a ter maior preocupação com a preparação para o exame, ao mesmo tempo em que os professores começaram a buscar apoio nos documentos oficiais para melhorar sua compreensão da Matriz de Competências e Habilidades do ENEM (BRASIL, 2012), dando maior importância para seu construto e reorientando práticas pedagógicas como um todo para que seu trabalho propicie aos seus alunos bons resultados no exame.

\subsection{Definindo construto}

Construto é um termo muito utilizado por pesquisadores na área de avaliação que se refere ao que será verificado ou mensurado, para que decisões possam ser tomadas. Primeiramente, esse conceito necessita ser bem definido para a elaboração de um exame ou teste e para a interpretação dos resultados (SCHOFFEN, 2009). Segundo Brown (2004, p. 25), "construto é qualquer teoria, hipótese, ou modelo que tenta explicar fenômenos observados em nosso universo de percepções". Ou seja, é a definição teórica que serve de base para a elaboração dos testes.

Ebel e Frisbie (1991, p. 108 apud Scaramucci, 2011, p. 32) conceituam que construto refere-se "a um construto psicológico, uma conceitualização teórica sobre um aspecto do comportamento humano que não pode ser medida ou observada diretamente". Conforme os autores, inteligência, motivação, ansiedade, atitude, compreensão em leitura, dentre outros fatores são exemplos de construto que são extremamente importantes para o aprendizado de língua estrangeira.

Fulcher e Davidson (2007) elucidam que, para que um termo abstrato seja considerado um construto, ele deve, em primeiro lugar, ser definido de 
forma a poder ser mensurado; em segundo lugar, deve ser possível relacionálo a algo observável de forma a estabelecer relações entre ele e outros construtos diferentes. Desse modo, o termo construto é utilizado para assinalar elementos abstratos como comportamento, habilidade ou conhecimento desejável, que possa ser retratado através de fontes de evidência ou indicadores. De acordo com Depresbíteris (2001, p. 33) os indicadores são

... evidências utilizadas para decidir se uma pessoa atendeu ou não aos critérios. Um indicador é um construto teórico, daí a necessidade de identificá-lo antes da análise de uma realidade. Cada critério define o que se julga poder esperar legitimamente do objeto avaliado. É por meio dos critérios que se pode realizar a 'leitura' do objeto.

Portanto, o construto tem o objetivo de tornar uma avaliação operacionalizável. O ENEM tem seu construto explicitado na sua Matriz de Referência (BRASIL, 2012). A leitura e interpretação de textos são adotadas por esse exame como as competências fundamentais para a resolução das questões. Observa-se a presença de uma grande variedade de textos multimodais, que são textos que inter-relacionam os recursos semióticos verbais e não verbais, conceitos sobre os quais discuto na próxima seção.

\section{A Teoria da Multimodalidade}

Segundo Kress e van Leeuwen (2006), a Semiótica Social é a base teórica dos estudos da Multimodalidade. Ela concebe as regras das linguagens como socialmente produzidas e mutáveis por meio da interação social. Essa teoria teve início com as pesquisas de Michael Halliday (1978), que afirmava que a linguagem não podia ser analisada de maneira isolada, desvinculada da sociedade e da cultura à qual pertence, pois a dimensão social é o ponto de partida para a análise. Maroun (2007, p. 91) contribui ao afirmar que "na Teoria da Semiótica Social, a língua é entendida como parte de um contexto sociocultural, no qual cultura é entendida como produto de um processo de construção social.” Nessa perspectiva, quatro suportes teóricos da abordagem multimodal são apontados por Jewitt (2009, p. 14-16): 
1) Os significados são produzidos e reproduzidos através de uma série de modos comunicativos e representacionais (gestos, olhar, imagem...)

2) Todos os modos semióticos (além da fala e da escrita) são moldados através de seus usos culturais, históricos e sociais.

3) As pessoas regem significados através de diferentes modos, e a interação destes é importante para a produção de novos significados.

4) Os significados dos signos realizados pelos modos semióticos são sociais.

Ao combinarem palavras com imagens, sons, ações e outros meios, Baldry e Thibault (2006) propõem modos de generalizar o método de Halliday (1978). Segundo esses autores, a linguagem é funcional, ou seja, está fazendo algum trabalho em algum contexto, ao contrário de palav ras e frases isoladas, concentra-se no social e na textualidade. Enfatiza todas as formas de significação da atividade social. O enfoque multimodal pretende compreender os diferentes modos de representação (VIEIRA, 2007).

Em relação a essa linguagem, diferentes recursos semióticos, como representação, gesto, sinal, movimento e música, se entrelaçam para fazer sentido. Eles funcionam juntos em um texto na forma como são combinados, pois há harmonia entre a linguagem verbal e não verbal. Segundo Dionísio (2005, p. 159), "imagem e palavra mantêm uma relação cada vez mais próxima, cada vez mais integrada".

Em conformidade com essa premissa, os textos nunca são monomodais, pois o princípio multimodal está difundido em todos os textos, em maior ou menor grau.

\subsection{0 texto multimodal}

Baldry e Thibault (2006) conceituam os textos multimodais como a parte constitutiva de algum evento de construção de significado ou atividade na qual o texto participa. Em outras palavras, é a parte inseparável das atividades de construção de significado, que envolvem muitos sistemas semióticos que interagem de diferentes formas em diferentes níveis de organização textual. 
Os textos multimodais combinam e integram os recursos de construção de significado de várias modalidades semióticas (linguagem, gesto, movimento, imagens visuais, som...) para produzir significados específicos do texto (BALDRY; THIBAULT, 2006).

Um aspecto fundamental da análise de texto multimodal é a intertextualidade, que se refere aos sistemas de relações de significado, que são comuns a um conjunto de textos. Os autores supracitados afirmam que as formações multimodais intertextuais, por exemplo, são construídas com base em recursos verbais e não verbais.

Desse modo, nenhum texto é feito ou interpretado isoladamente de outros textos. O texto multimodal possui um papel socialmente significativo. Ele explora várias semioses e, como consequência, é possível afirmar que a Multimodalidade extrapola muitas possibilidades para se trabalhar com os diversos gêneros discursivos, como anúncios publicitários, tirinhas, filmes, músicas, reportagens, entre outros.

A proposta de inserir, no ENEM, leitura e interpretação de textos baseados em gêneros discursivos (BAKHTIN, 1999), em princípio, propicia a prática social de leitura e possibilita maior expressão verbal (oral ou escrita) do aprendiz (DELL'ISOLA, 2009).

Bakhtin (1999) classifica o gênero primário como as formas genéricas básicas características de ampla gama de situações sociais encontradas na vida cotidiana (troca dialógica, cartas pessoais, memorandos, instruções, explicações, entre outros) e o secundário como formas complexas de discurso (textos científicos, artísticos, jornalísticos,...). Nessa perspectiva, segundo Baldry e Thibault (2006), a distinção que Bakhtin (1999) faz entre gêneros primários e secundários pode ser estendida para textos multimodais. Para os autores, gêneros são conceituados como formas típicas de discurso que são usados de acordo com a situação de fala.

Portanto, a inserção, no ENEM, de diversos gêneros discursivos, com potencialidades de significação, e combinação dos recursos semióticos, contribui para a construção de sentido do texto multimodal, tornando-o mais eficaz no processo ensino/aprendizagem de línguas. Para o Parâmetro Curricular Nacional do Ensino Médio (PCN) (BRASIL, 2002, p. 96), 
... a análise de textos de diferentes gêneros (slogans, quadrinhos, poemas, notícias de jornal, anúncios publicitários, textos de manuais de instrução, entre outros), vazados em língua estrangeira, permite a consolidação do conceito e o reconhecimento de que um texto só se configura como tal a partir da articulação de determinados elementos, de uma intencionalidade, explícita ou não, e de um contexto moldado por variáveis socioculturais.

Essa escolha favorece prática social de leitura, que permite conhecimento da cultura da língua-alvo e também cria condições para a expressão verbal e não verbal do aprendiz (DELL'ISOLA, 2009). Assim, apresentamos, a seguir, algumas considerações sobre o construto do texto multimodal em questões de inglês e espanhol do ENEM, que serão o foco de análise deste artigo.

\subsubsection{O construto do texto multimodal no ENEM}

Ao longo dos anos, os textos multimodais têm sido mais explorados nas provas do ENEM. É possível observar a presença de uma grande variedade desses textos, em que se busca avaliar a capacidade de leitura e interpretação de recursos verbais e não verbais.

Nesse sentido, evidenciamos, neste artigo, o construto do texto multimodal no ENEM das questões de língua estrangeira e, como base teórica, consultamos dois documentos: a fundamentação teóricometodológica do ENEM (BRASIL, 2005) e a Matriz de Referência do ENEM (BRASIL, 2012).

A fundamentação teórico-metodológica do ENEM (BRASIL, 2005) é clara ao sugerir a leitura de textos verbais e não verbais, atentando-se para textos que vão além da leitura de códigos linguísticos, “o exame propõe-se a avaliar e analisar a própria operação de ler, seus modos e tipos que ultrapassam os limites da decifração lingüística e adentram em um campo semiótico amplo, responsabilizando todos os envolvidos na produção da prova com essa avaliação" (BRASIL, 2005, p. 59). Desse modo, o documento sinaliza para a importância de adentrar em um "campo semiótico amplo", em que os textos multimodais integram diferentes recursos semióticos que 
são combinados para produzir um significado global textual (BALDRY; THIBAULT, 2006).

A Matriz de Referência do ENEM (BRASIL, 2015) evidencia as diversas competências e habilidades necessárias para a execução da prova. $\mathrm{Na}$ área de Linguagens, Códigos e suas Tecnologias, a Matriz é dividida em competências de nove áreas, que se subdividem em 30 habilidades. No entanto, destacamos as competências de área dois e sete, que enfatizam, respectivamente, as línguas estrangeiras e o pressuposto da leitura de textos verbais e não verbais, conforme se pode observar no Quadro 1.

No Quadro 1, é possível perceber como a competência e as habilidades se relacionam, o que evidencia o conhecimento e o uso da língua, e a importância de compreender as diferentes linguagens em proveito da comunicação. Na Habilidade 21 (H21) é possível perceber a forte tendência para a presença da multimodalidade no exame. Nesse sentido, a fundamentação teórico-metodológica do ENEM contribui ao afirmar que "todas as situações de avaliação estruturam-se de modo a verificar se o aluno é capaz de ler e interpretar textos em linguagem verbal e visual (fotos, mapas, pinturas, gráficos, entre outros) e enunciados" (BRASIL, 2005, p. 59).

Então, torna-se necessário sensibilizar os professores para que dediquem uma atenção maior para a descrição e categorização da linguagem visual e da Teoria da Multimodalidade, que permite uma leitura que ultrapassa o linguístico e propicia muitas construções de significados. 
Quadro 1: Matriz de referência ENEM

\begin{tabular}{|c|c|c|}
\hline \multicolumn{3}{|c|}{ Matriz de Referência de Linguagens, Códigos e suas Tecnologias } \\
\hline Competência & $\begin{array}{l}\text { 2- Conhecer e usar } \\
\text { língua(s) estrangeira(s) } \\
\text { moderna(s) como } \\
\text { instrumento de acesso a } \\
\text { informações e a outras } \\
\text { culturas e grupos sociais. }\end{array}$ & $\begin{array}{l}\text { 7- Confrontar opiniões e } \\
\text { pontos de vista sobre as } \\
\text { diferentes linguagens e } \\
\text { suas manifestações } \\
\text { específicas. }\end{array}$ \\
\hline \multirow{4}{*}{ Habilidades } & $\begin{array}{l}\text { H5 - Associar } \\
\text { vocábulos e expressões } \\
\text { de um texto em LEM ao } \\
\text { seu tema. }\end{array}$ & \multirow{4}{*}{$\begin{array}{l}\text { H21 - Reconhecer em } \\
\text { textos de diferentes } \\
\text { gêneros, recursos verbais } \\
\text { e não verbais utilizados } \\
\text { com a finalidade de criar e } \\
\text { mudar comportamentos e } \\
\text { hábitos. }\end{array}$} \\
\hline & $\begin{array}{l}\text { H6 - Utilizar os } \\
\text { conhecimentos da LEM } \\
\text { e de seus mecanismos } \\
\text { como meio de ampliar } \\
\text { as possibilidades de } \\
\text { acesso a informações, } \\
\text { tecnologias e culturas. }\end{array}$ & \\
\hline & $\begin{array}{l}\text { H7 - Relacionar um } \\
\text { texto em LEM, as } \\
\text { estruturas linguísticas, } \\
\text { sua função e seu uso } \\
\text { social. }\end{array}$ & \\
\hline & $\begin{array}{l}\text { H8 - Reconhecer a } \\
\text { importância da } \\
\text { produção cultural em } \\
\text { LEM como } \\
\text { representação da } \\
\text { diversidade cultural e } \\
\text { linguística. }\end{array}$ & \\
\hline
\end{tabular}

Fonte: BRASIL/INEP, 2012.

\subsection{O Multiletramento}

O letramento está diretamente ligado às práticas sociais, em que o usuário da linguagem é detentor de habilidades de escrita e leitura que 
contribuem para sua formação crítica (PASSARELI, 2011). Nessa perspectiva, Scribner e Cole (1981) conceituam letramento como o conjunto de práticas sociais que se valem da escrita, em contextos específicos, para atingir determinados objetivos.

No entanto, em relação aos textos multimodais, essa noção restrita de letramento como apropriação da leitura e da escrita em contexto social não se mostra a mais adequada. Atualmente a noção de letramento é abrangente, e é denominada multiletramento (COPE; KALANTZIS, 2000). Vieira (2007, p. 24) contribui ao afirmar que "o letramento hoje não se refere, apenas, às habilidades de leitura e escrita. O letramento típico da pós-modernidade agrega ao texto escrito inúmeros recursos gráficos, cores e, principalmente, imagens".

Segundo Cope e Kalantzis (2000), o multiletramento envolve conhecimento linguístico-discursivo associado a conhecimento visual, espacial, digital e posicionamento crítico. Esses autores afirmam ainda que a interação desses conhecimentos promove o que se chama de letramento multimodal (COPE; KALANTZIS, 2000).

Assim, com a importância concedida ao visual e a ampla noção de multiletramento, outros variados modos semióticos de representação que contribuem para a construção de sentido são destacados. Consequentemente, novas competências e habilidades são necessárias aos alunos. Nesse sentido, as Orientações Curriculares para o Ensino Médio (BRASIL, 2006, p. 29) ressaltam:

... pode se ater ao letramento da letra, mas deve, isso sim, abrir-se para os múltiplos letramentos, que, envolvendo uma enorme variação de mídias, constroem-se de forma multissemiótica e híbrida [...]. Reiterase que essa postura é condição para confrontar o aluno com práticas de linguagem que o levem a formar-se para o mundo do trabalho e para a cidadania com respeito pelas diferenças no modo de agir e de fazer sentido.

O letramento é um processo em contínuo desenvolvimento, por isso pensar as práticas de multiletramento implica assumir novas concepções de linguagem. No tocante aos textos multimodais na prova do ENEM, é 
necessário saber como imagens e demais recursos gráficos se estruturam, se organizam, e se inter-relacionam, ampliando o significado para além da informação linguística presente no texto.

O multiletramento torna-se de suma importância para a sociedade atual, pois se espera que o sujeito não reproduza apenas conceitos, mas que atue na sociedade buscando transformá-la significativamente (SILVA, 2015).

$\mathrm{Na}$ próxima seção, discutimos as questões metodológicas deste trabalho.

\section{Metodologia}

Este artigo relata uma pesquisa de natureza qualitativa. Conforme Flick (2009, p. 23), a pesquisa qualitativa trabalha, sobretudo, "com a escolha adequada de métodos e teorias convenientes; [...] nas reflexões dos pesquisadores [...]; e na variedade de abordagens e métodos". Nessa perspectiva, os métodos de interpretação, comparação e descrição do artigo serão a partir dos textos do aporte teórico. Ludke (1986, p. 1) reitera que "para se realizar uma pesquisa é preciso promover o confronto entre os dados, as evidências, as informações coletadas, sobre determinado assunto e o conhecimento teórico acumulado a respeito dele". Desse modo, o estudo, caracteriza-se como estudo de caso interpretativista. E define-se por investigação detalhada do objeto analisado e suas relações com o contexto no qual está inserido.

Baseadas nisso, analisamos, neste artigo, quatro questões de inglês e espanhol dos ENEM de 2013, 2014 e 2015, considerando-as como textos multimodais, uma vez que assumimos a abordagem proposta por Kress e van Leuween (1996), que definem o texto multimodal como aquele que tem seus significados realizados por meio de mais de uma semiose.

A análise é baseada na perspectiva da Análise de Clusters (BALDRY; THIBAULT, 2006), que possibilita observar a interação dos recursos semióticos entre a semiose verbal e não verbal.

Na sequência, a análise das questões selecionadas para este estudo. 


\section{Análise de Questões Multimodais}

Um texto multimodal integra diferentes recursos semióticos como elementos visuais, espaciais e linguísticos em vários níveis de organização textual, e os diversos tipos de recursos são combinados na construção de significados.

Esses textos possibilitam várias análises multimodais e, dentre estas, destaca-se a análise de Clusters que, segundo Baldry e Thibault (2006, p. 31), "é um termo que se refere a um agrupamento local dos itens, em uma página”. Os itens para multimodalidade são os recursos semióticos (verbais ou não verbais) que se inter-relacionam.

Desse modo, analisar clusters ajuda a visualizar, em uma abordagem macro, como esses clusters estão contidos dentro de outros maiores e também, de forma mais detalhada, a disposição dos itens multimodais de maior escala e os de menor escala. Esta análise é uma ferramenta muito importante para a compreensão de como recursos semióticos estão dispostos na página e como interagem para produzir significados. A abordagem macro traz à tona os aspectos sociais do texto multimodal que foi inserido na prova do ENEM (campanha comunitária, sítio eletrônico, tirinha etc.).

Nas análises, apresentamos três clusters em destaque (marcados em azul nas figuras) com potencialidades de significação presentes em cada questão. Eles são interdependentes e há uma relação funcional que define a trajetória de leitura e permite múltiplas articulações na construção do sentido. Vejamos a Figura 2, que apresenta uma questão de espanhol do ENEM aplicado em 2013. 


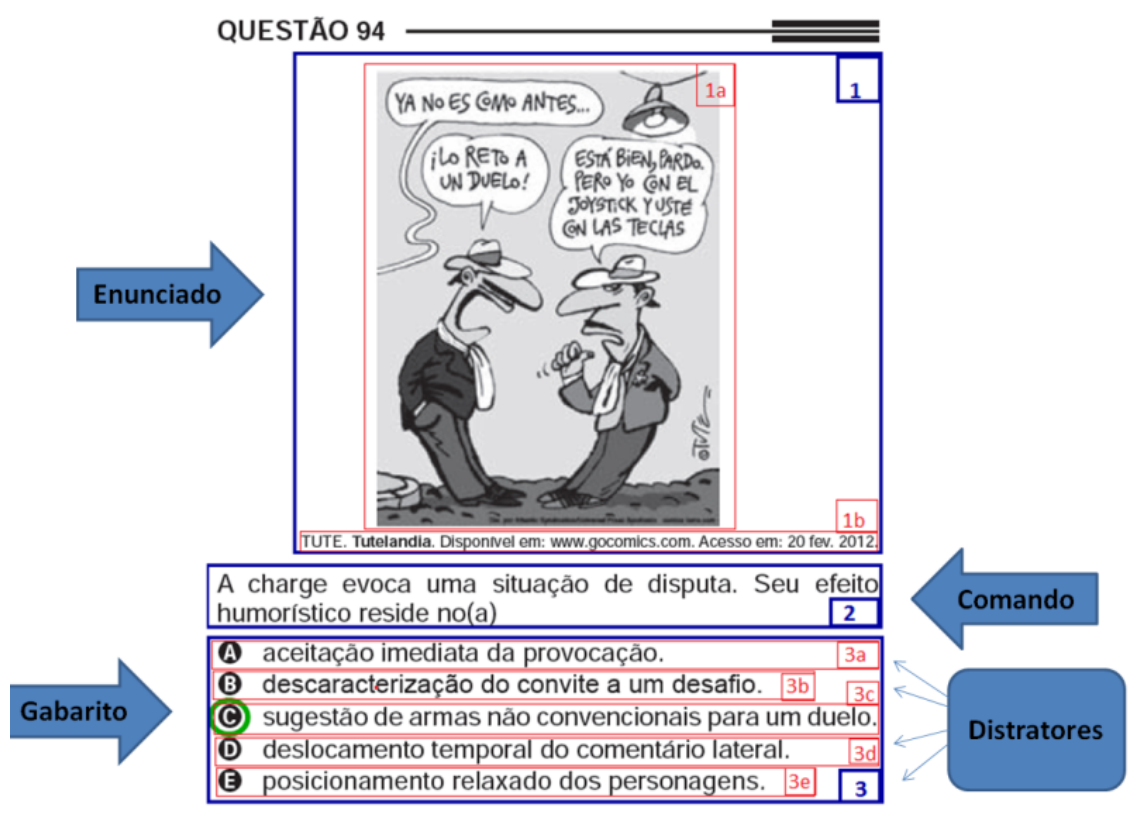

Fonte: ENEM 2013.

Figura 2: Questão de Língua Espanhola 2013

O cluster 1 (marcado em azul na Figura 2) é o que chamamos de enunciado, que apresenta uma charge sobre uso de novas tecnologias. O gênero em questão é uma ilustração humorística, que envolve a caricatura de um ou mais personagens, e tem como finalidade satirizar algum acontecimento da atualidade. Na maioria das vezes, as críticas são de cunho político-social.

Desse modo, no subcluster 1a (marcado em vermelho), destaca-se a charge, em que a imagem está em primeiro plano e evoca a uma situação de disputa. A expressão corporal e facial dos personagens nos indica uma discussão. No aspecto verbal, percebe-se já no primeiro balão "Ya no es como antes...", uma comparação com o antigo e o moderno. $\mathrm{Na}$ discussão, um personagem deixa claro que se trata de um "duelo", remetendo-nos aos duelos de filme de faroeste, e outro expõe as armas que serão utilizadas "joystick e teclado". 
O cluster 2 refere-se ao comando da questão, que evidencia, na pergunta, o gênero charge e seu construto, em que o candidato precisa analisar em que consiste seu efeito humorístico. Assim, o construto por trás do item referese ao "H21 - Reconhecer em textos de diferentes gêneros, recursos verbais e não verbais utilizados com a finalidade de criar e mudar comportamentos e hábitos" (BRASIL, 2012, p. 2), que avalia o conhecimento reflexivo e crítico do candidato.

No cluster 3, há quatro alternativas: a correta (subcluster 3c), que denominamos gabarito, evidencia que o efeito humorístico da charge consiste na sugestão de armas não convencionais para um duelo, baseada no conhecimento e na tecnologia; e as incorretas (3a, 3b, 3d, 3e), denominadas distratores, que precisam representar hipóteses plausíveis para candidatos que ainda não dominam o descritor do item.

A partir da análise, observamos que o gênero discursivo charge apresenta aspectos relevantes verbais e não verbais. As potencialidades de significação dos recursos semióticos nos textos multimodais podem ser utilizadas ou trabalhadas na sala de aula, o que potencialmente causaria um efeito retroativo positivo. Os recursos semióticos, como as imagens, as expressões corporal e facial, as falas, se bem explorados, podem ajudar significativamente o leitor no processo de compreensão textual. Desse modo, para ampliar a discussão, selecionamos a próxima questão para análise.

$\mathrm{Na}$ Figura 3, o enunciado da questão possui apenas a modalidade verbal, e propositalmente a selecionamos, com a finalidade de apresentar que o princípio multimodal é difundido em todos os textos, e que não há texto monomodal. Nessa perspectiva, no cluster 1 é apresentado o gênero texto informativo. O objetivo principal desse gênero é transmitir informação, de maneira clara e objetiva, sobre determinado tema.

No texto, é possível observar que, para produzir um significado global, variados recursos são combinados, como os diferentes tipos e tamanhos de letras. Por exemplo, no subcluster 1a, observamos ênfase no título com a presença de datas, que está em destaque, com letras maiores e em negrito, indicando que a temática é a vida de Steve Jobs. O subcluster $1 \mathrm{~b}$, também em destaque, mas agora com outro tipo de letra e em itálico, informa que o texto falará da sua contribuição para o mundo digital, e isso é possível identificar apenas com os cognatos "contribution" e "digital". 


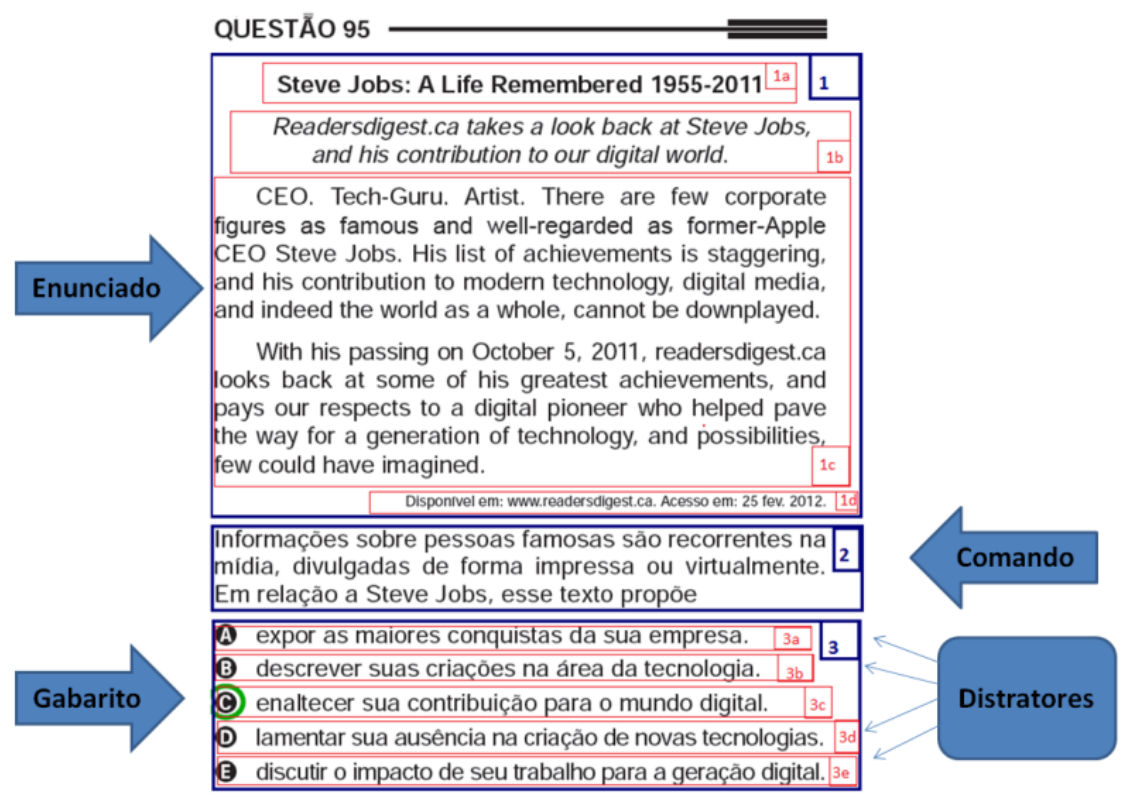

Fonte: ENEM 2013.

Figura 3: Questão de Língua Inglesa 2013

No cluster 2 o comando revela o gênero e a temática do item sobre Steve Jobs. Seu construto está relacionado à habilidade "H6 - Utilizar os conhecimentos da LEM e de seus mecanismos como meio de ampliar as possibilidades de acesso a informações, tecnologias e culturas" (BRASIL, 2012 , p. 2). A compreensão do subtítulo e de alguns adjetivos torna-se importante para a resolução da questão.

Desse modo, no cluster 3, com as alternativas, fica evidente que saber como os recursos semióticos se combinam ajudam o candidato a entender o texto. E, para chegar à resposta correta (subcluster 3c), é necessária também uma análise dos distratores, pois, além de enaltecer Steve Jobs, dando a ele vários adjetivos, o texto também ressalta seu pioneirismo no mundo digital, sendo possível compreender essa informação através do cognato "digitalpionner". 
Com a análise é possível constatar que o tipo e tamanho de letra, distribuição dos elementos na página contribuem também para a construção de sentido do texto. Nesse sentido, um efeito retroativo positivo nas salas de aula de línguas estrangeiras seria as habilidades textuais acompanhar as novas formas de multiletramento, ultrapassando o linguístico, e agregando habilidades interpretativas multimodais.

Nessa perspectiva de análise, selecionamos também duas questões de língua estrangeira do ENEM 2014. Em ambas destacamos, da mesma ,forma três clusters, como é possível visualizar na Figura 4, que apresenta uma questão de espanhol do ENEM 2014.

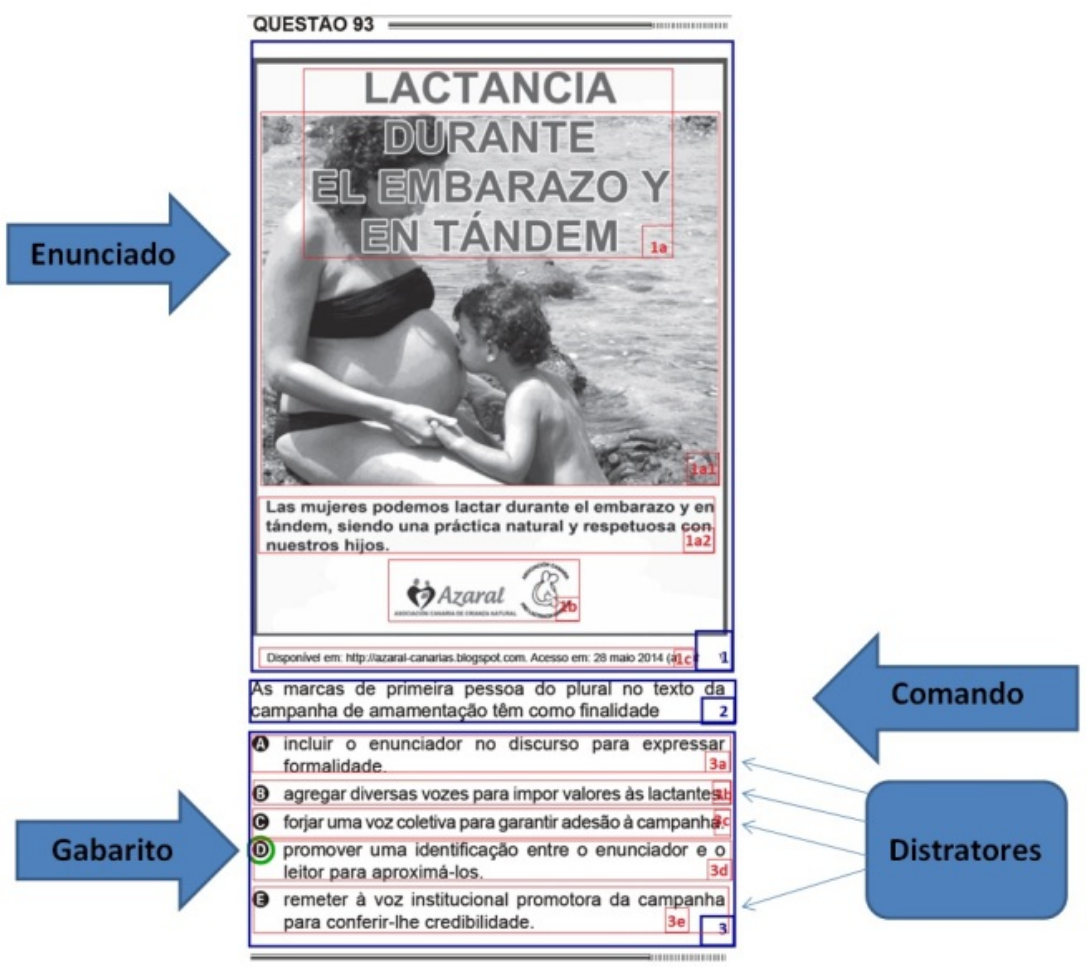

Fonte: ENEM 2014.

Figura 4: Questão de Língua Espanhola 2014 
O cluster 1 apresenta, no seu enunciado, uma campanha comunitária sobre amamentação infantil e sua importância, composto por vários subclusters (marcados em vermelho na Figura 4), referente aos elementos que compõem essa campanha. O gênero textual em questão tem como finalidade informar, esclarecer e orientar as pessoas sobre um determinado tema e persuadi-las a participar. Desse modo, no subcluster 1a, destaca-se a frase motivadora "Lactancia durante el embarazo y en tándem" que está em posição centralizada na parte superior, em letras maiúsculas, destacadas no primeiro plano. Outro aspecto que se destaca na campanha é a imagem em segundo plano presente no subcluster 1a1, que revela claramente a interação entre texto e imagem. No subcluster 1a2, a primeira pessoa do plural é empregada "una práctica natural y respetuosa con nuestros hijos", revelando, assim, a intenção de se criar uma voz coletiva, aproximando o enunciador do leitor.

No comando da questão, o cluster 2 deixa claro, na pergunta, o gênero campanha publicitária e seu construto, em que o candidato precisa analisar a última frase da campanha relativa à primeira pessoa do plural. Desse modo, o construto por trás do item refere-se ao "H7 - Relacionar um texto em LEM, as estruturas linguísticas, sua função e seu uso social” (BRASIL, 2012, p. 2), que avalia o conhecimento linguístico do candidato.

No cluster 3, há cinco alternativas: a correta (subcluster 3d), denominada gabarito, e as incorretas (3a, 3b, 3c, 3e), denominadas distratores, que precisam representar hipóteses plausíveis para candidatos que ainda não dominam o descritor do item.

Com base na análise, observamos que o gênero discursivo campanha publicitária apresenta ricos elementos de linguagem verbal e não verbal. A relação entre imagem e texto, se bem explorados em sala de aula, podem contribuir para o processo de compreensão e interpretação textual. Conhecer as potencialidades de significação dos recursos semióticos pode suscitar um possível efeito retroativo positivo na escola.

O próximo item analisado também é composto por três clusters, como podemos observar na Figura 5, que mostra uma das questões de inglês do ENEM 2014. 


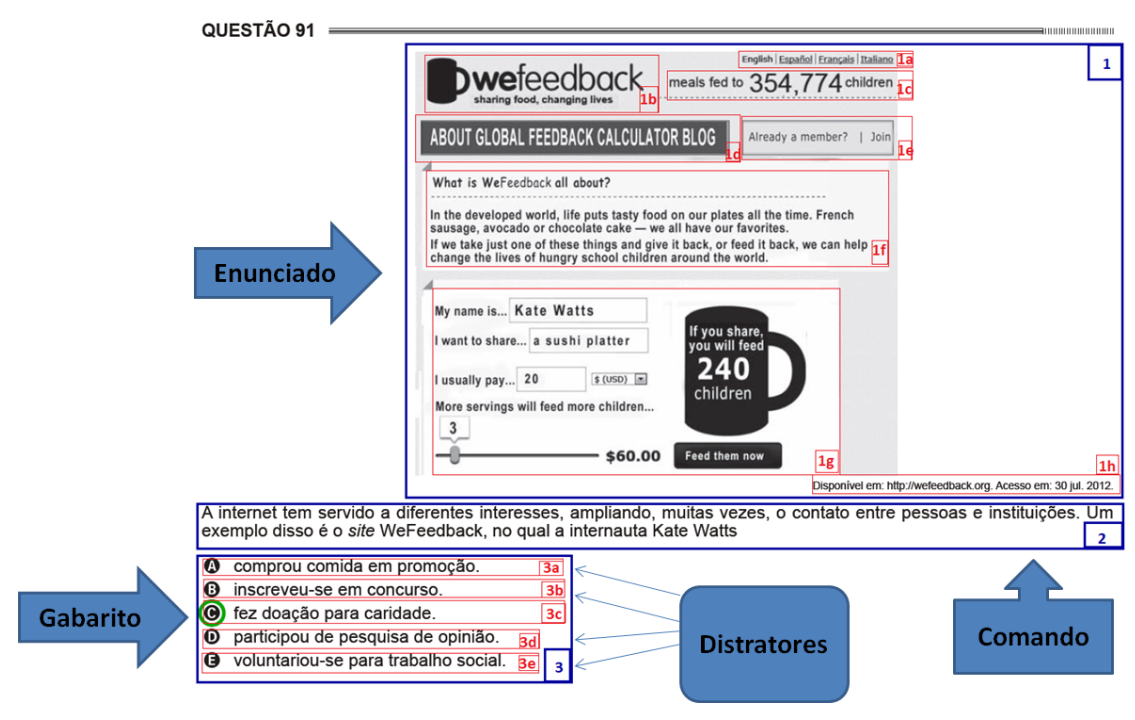

Fonte: ENEM 2014.

Figura 5: Questão de Língua Inglesa 2014

O cluster 1 apresenta, em seu ,enunciado o sítio eletrônico "WeFeedback", destacado no subcluster 1b. Em relação a esse gênero, é importante enfatizar que sua lógica organizacional é diferente de uma página impressa. Sua leitura não é linear, posto que há possibilidade de acessar outros conteúdos (e, consequentemente, outras semioses) e a abertura de links e hiperlinks é infinita. Nessa perspectiva, outro aspecto relevante a se observar é a ressemiotização que "refere-se a como os significados mudam de contexto para contexto, de prática para prática, ou de um estágio de uma prática para outra" (IEDEMA, 2003, p. 41). Desse modo, ao sair do seu contexto de origem, o gênero sítio eletrônico é ressemiotizado para outro contexto (prova do ENEM), ganhando novas semioses.

Na prova, o sítio eletrônico possui uma leitura linear. Essa página da internet tem como finalidade angariar doações que serão revertidas para comprar comida para crianças carentes, conforme o texto do subcluster $1 \mathrm{f}$. O subcluster $1 \mathrm{~g}$ retrata uma internauta chamada Kate Watts que estaria na página doando 60 dólares, o que ajudaria a alimentar 240 crianças. Essa última 
informação é apresentada em uma xícara em destaque, simbolizando o leite que essas crianças beberão.

No cluster 2, o comando é claro ao explicitar que seu objetivo é saber o que a internauta fez no sítio eletrônico. Seu construto refere-se à habilidade "H6 - Utilizar os conhecimentos da LEM e de seus mecanismos como meio de ampliar as possibilidades de acesso a informações, tecnologias e culturas" (BRASIL, 2012, p. 2). Encontramos, então, no cluster 3, o gabarito no subcluster 3c "fez doação para caridade" e seus distratores nos subclusters 3a, 3b, 3d, e 3e, em que as alternativas são plausíveis.

Os próprios recursos semióticos auxiliam na construção de sentido para a resolução da questão. A análise possibilita evidenciar que aspectos suscitados pelo ENEM, como as mídias digitais, podem levar o professor a incorporar novas práticas de ensino, chamando a atenção dos alunos para elementos visuais, espaciais e digitais.

Nesse sentido, selecionamos ainda mais duas questões de língua estrangeira, do ENEM 2015.

Na Figura 6, O cluster 1 desse item é um cartaz publicitário, em que é possível observar o verbal e o não verbal como recursos semióticos que se complementam. No entanto, o verbal, no subcluster $1 \mathrm{a}$, aparece em primeiro plano, em posição centralizada na parte superior, sobrepondo-se à imagem, que está em segundo plano, símbolo da acessibilidade pintada no chão, remetendo-nos à imagem que normalmente observamos em um estacionamento, por exemplo, no subcluster $1 \mathrm{~b}$.

No cluster 2 o comando explicita a temática do item sobre acessibilidade. Seu construto está relacionado à habilidade "H6 - Utilizar os conhecimentos da LEM e de seus mecanismos como meio de ampliar as possibilidades de acesso a informações, tecnologias e culturas" (BRASIL, 2012, p. 2). A compreensão da frase "Se você fica com minha vaga, fique também com minha deficiência - não aumente minhas barreiras" torna-se importante para a resolução da questão. No entanto, uma análise atenta da imagem levaria também a uma possível resposta correta.

Dessa forma, no cluster 3 há uma plausibilidade nas alternativas, em que todas citam a palavra cadeirante e falam sobre acessibilidade. Além da leitura da imagem, saber o significado da palavra "aparcamiento" é outro ponto-chave para a resolução e construção de sentido, já que o gabarito no subcluster 3b é "respeitar o estacionamento destinado a cadeirante". 


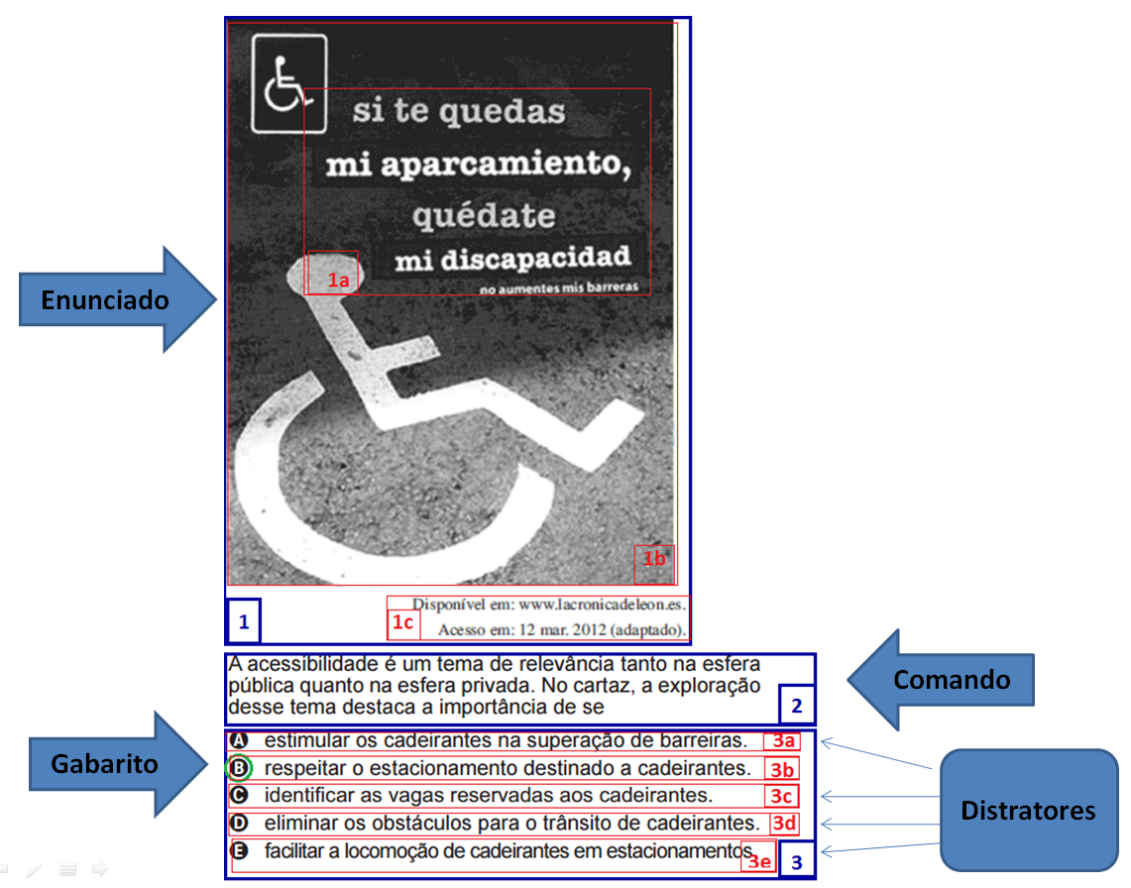

Fonte: ENEM 2015.

Figura 6: Questão de Língua Espanhola 2015

Com a análise é possível constatar que variados recursos semióticos, como cores, tipo de letra, imagens, relação entre imagem e texto verbal e distribuição dos elementos na página contribuem significativamente para a construção de sentido do texto. Nessa perspectiva, um efeito retroativo positivo nas salas de aula de línguas estrangeiras seria o desenvolvimento de novas competências e habilidades, nos alunos, que ultrapassam o linguístico. Por exemplo, saber como imagens e recursos gráficos se estruturam, se organizam, e se inter-relacionam para produzir sentidos.

Na prova de língua inglesa de 2015, selecionamos a questão 92 para análise. Vejamos a Figura 7: 


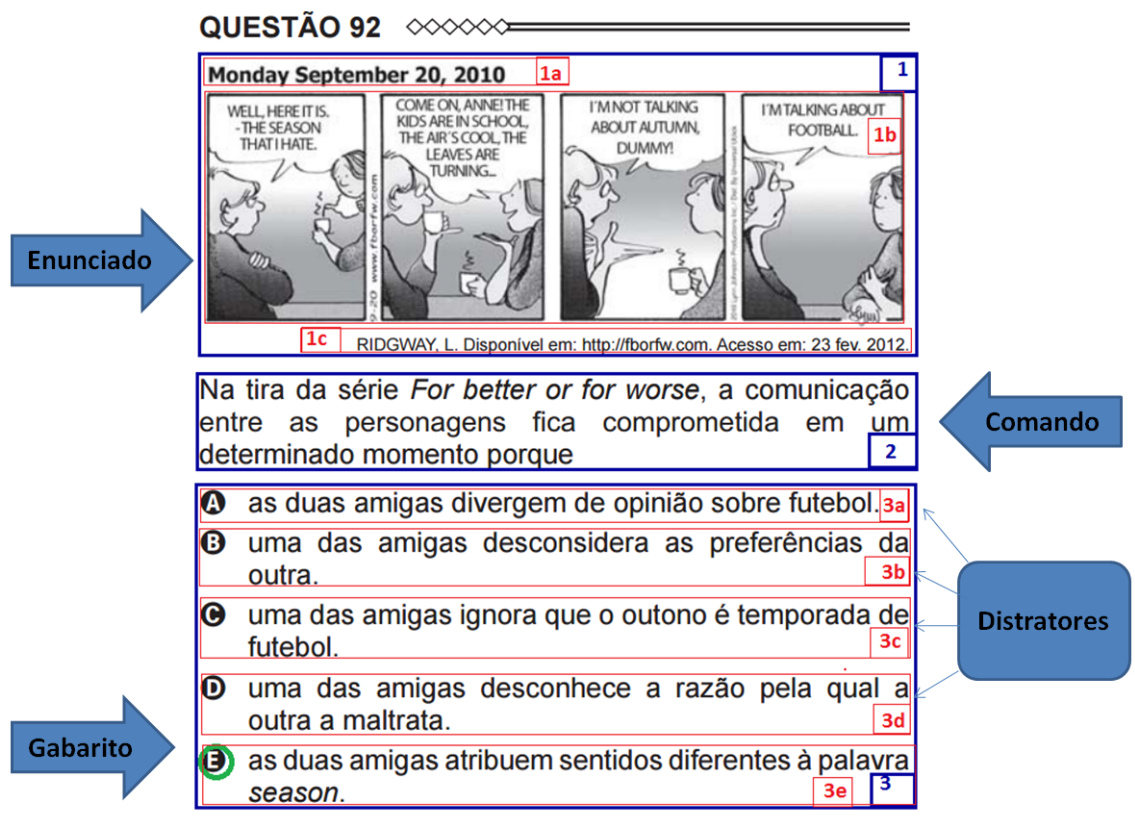

Fonte: ENEM 2015.

Figura 7: Questão de Língua Inglesa 2015

O cluster 1 refere-se à tira da série "For better or for worse", e os recursos semióticos nos levam a inferir uma conversa trivial entre duas amigas.

No cluster 2, o comando evidencia que a comunicação entre as personagens é comprometida em um determinado momento e busca saber a razão de tal comprometimento. O primeiro quadrinho já dá pistas do assunto sobre o qual as amigas estão falando, e a comunicação entre elas fica comprometida no momento em que ambas atribuem sentidos diferentes à palavra "season".

O construto dessa questão pressupõe a verificação de conhecimento lexical e refere-se à habilidade "H5 - Associar vocábulos e expressões de um texto em LEM ao seu tema" (BRASIL, 2012, p. 2). O item trabalha com a polissemia da palavra "season”, que pode significar temporada ou estação do ano. Dessa forma, uma das personagens atribuiu o sentido de temporada para a palavra "season", referindo-se à temporada de futebol, e a outra 
personagem entendeu “season” como estação do ano, comprometendo, então, a comunicação entre elas.

No cluster 3, com as alternativas, fica evidente que os recursos semióticos não ajudam muito o candidato a entender o texto, pois não há pistas além das linguísticas. Por isso, para chegar à resposta correta (subcluster 3e) é necessária a análise dos distratores e ter conhecimentos linguísticos.

Mesmo em uma questão com enfoque predominantemente linguístico como essa, que utiliza o gênero tirinha, os elementos não verbais são sempre de grande relevância, pois esse gênero caracteriza-se por um conjunto de vinhetas que apresentam alguma situação, em geral cômica, e também crítica. Assim, outro efeito retroativo positivo para a sala de aula de línguas estrangeiras seria desenvolver o conhecimento linguístico-discursivo dos alunos, associado a conhecimentos multimodais e a posicionamento crítico. Isso significa dizer que o trabalho com o multiletramento pode levar os alunos a atentarem para todos os aspectos do texto apresentado.

As análises das questões trazem à tona aspectos suscitados pelo ENEM que, em muitos momentos, passam despercebidos aos olhos dos candidatos, e que podem ser utilizados ou trabalhados em classe.

\section{Considerações Finais}

As análises permitem reflexão sobre o texto multimodal no ENEM e seu efeito retroativo potencial, demonstrando as peculiaridades tanto inerentes ao tipo de gênero discursivo como de composição semiótica.

Há um número significativo de textos multimodais na prova do ENEM (MARENCO, 2014) e é possível que, ao longo dos anos, esses textos possam impactar positivamente o sistema educacional. Nesse sentido, é importante que a escola desenvolva multiletramentos e procure ir além do ensino de leitura de textos verbais.

Essa perspectiva exige que o ensino se reorganize também em função do desenvolvimento de habilidades e competências cognitivas. Como afirma Bachman (1990, p. 291), é preciso “ir além das teorias lingüísticas e psicométricas e considerar as funções sociais e políticas dos testes [...]. Devem-se considerar as conseqüências, tanto positivas quanto negativas". O enfoque multimodal visa a transpor o ensino relacionado apenas à modalidade 
verbal, e concentra-se na textualidade, nas origens sociais, na produção do texto e na sua leitura (VIEIRA, 2007), por isso é importante que o professor esteja atento a esses fenômenos da multimodalidade e se preocupe em identificar as melhores formas de utilização das capacidades cognitivas envolvidas (DIONISIO; VASCONCELOS, 2013).

Dessa forma, as práticas de multiletramento consideram que os professores devem conduzir os alunos a se tornarem produtores e não apenas consumidores de conhecimento (COPE; KALANTZIS, 2007). Os multiletramentos favorecem a construção de um conhecimento vinculado à experiência humana, e estão estreitamente ligados a questões concretas do cotidiano dos alunos que podem envolver um trabalho interdisciplinar.

Baseado nesse potencial impacto positivo de textos multimodais, no ENEM, espera-se que "escola forme sujeitos cujo letramento promova significativa inserção sociocultural, a fim de que possam interagir com sucesso na vida escolar e na vida em sociedade" (PASSARELLI, 2011, p. 15). É necessário, portanto, uma prática didático-pedagógica que estimule os novos modos de significar, de fazer sentido e de fazer circular discursos na sociedade atual, visando os multiletramentos e enfatizando a composição da linguagem verbal e não verbal, que envolve várias combinações de recursos semióticos, com importante função comunicativa. $\mathrm{O}$ trabalho com a multimodalidade pode ser estimulante tanto para o aluno quanto para o professor, uma vez que traz novas perspectivas para o processo de ensino-aprendizagem de LE.

\section{Referências}

ALDERSON, J. C.; WALL, D. Does washback exist? Working Paper Series 11. CRILE, Lancaster University. Republicado em Applied Linguistics, v. 14, p. 115-129, 1993.

BACHMAN, L. Fundamental considerations in language testing. Oxford: Oxford University Press, 1990.

BACHMAN, L. F.; PALMER, A. S. Language testing in practice: designing and developing useful language tests. Oxford: University Press, 1996. 
BAKHTIN, M. Marxismo e filosofia da linguagem. São Paulo: Hucitec, 1999.

BALDRY, A.; THIBAULT, P. J. Introduction: multimodal texts and genres. In: BALDRY, A.; THIBAULT, P. J. Multimodal transcription and text analysis: a multimedia toolkit and coursebook. London: Equinox, 2006. p. 1-56.

BLASIS, E. (Org.) Avaliação educacional: os desafios da sala de aula e a promoção da aprendizagem. São Paulo: Cenpec; Fundação Itaú Social, 2014.

BRASIL. Ministério da Educação. Secretaria de Educação Básica. Orientações curriculares para o ensino médio: Linguagens, códigos e suas tecnologias. Brasília: MEC; SEB, 2006.

BRASIL. Instituto Nacional de Estudos e Pesquisas Educacionais Anísio Teixeira (INEP). Exame Nacional do Ensino Médio (Enem): fundamentação teórico-metodológica do ENEM. Brasília, 2005. Disponível em: <http:// www.publicacoes.inep.gov.br/portal/download/407>. Acesso: 29 nov. 2015.

BRASIL. Instituto Nacional de Estudos e Pesquisas Educacionais Anísio Teixeira (INEP). Exame Nacional do Ensino Médio (Enem). Disponível em: $<$ http://www.vestibulandoweb.com.br/enem/vestibular-provasenem.asp>. Acesso em: 29 nov. 2015.

BRASIL. Instituto Nacional de Estudos e Pesquisas Educacionais Anísio Teixeira. Matriz de competências para o Enem 2013. Ministério da Educação. Brasília, 2012. Disponível em: <http://download.inep.gov.br/ educacao_basica/enem/downloads/2012/matriz_referencia_enem.pdf $>$. Acesso: 29 nov. 2015.

BRASIL. Ministério da Educação. Secretaria da Educação Média e Tecnológica. Parâmetros Curriculares Nacionais + (PCN+) - Linguagens, Códigos e suas Tecnologias. Brasília: MEC, 2002. Disponível em: <http:/ /portal.inep.gov.br/web/saeb/parametros-curriculares-nacionais >. Acesso em: 02 fev. 2016. 
BRASIL. Ministério da Educação. Secretaria de Educação Básica. Orientaçôes Curriculares para o Ensino Médio - Linguagens, Códigos e tecnologias. Brasília: MEC, 2006. Disponível em: <http:// portal.mec.gov.br/seb/arquivos/pdf/book_volume_01_internet.pdf $>$. Acesso em: 12 abr. 2016.

BROWN, H. D. Language assessment: principles and classroom practices. White Plains, NY: Pearson Education; Longman, 2004.

CHENG, L. The washback effect of a public examination change on teachers' perceptions toward their classroom teaching. In: CHENG, L.; WATANABE, Y,; CURTIS, A. (Ed.). Washback in language testing: research contexts and methods. Mahwah, NJ: Lawrence Erlbaum Associates, 2004. p. $147-170$.

COPE, B.; KALANTZIS, M. Introduction: Multiliteracies: the beginnings of an idea. In: COPE, B.; KALANTZIS, M. (Ed.) Multiliteracies: literary learning and the design of social futures. London: Routledge, 2000. p. 337.

COPE, B.; KALANTZIS, M. New Media, New Learning. International Journal of Learning, v. 14, n. 1, p. 75-79, 2007. Disponível em: <http:// newlearningonline.com/kalantizissandcope/research-and-writing/ $>$. Acesso em: 23 de jan. 2017.

DELL'ISOLA R. L. P. Gêneros textuais em livros didáticos de português língua estrangeira: o que falta? In: DIAS, R.; CRISTOVÃO, V. L. P. (Org.). O livro didático de língua estrangeira: múltiplas perspectivas. Campinas: Mercado de Letras, 2009. p. 99-120.

DEPRESBÍTERIS, L. A avaliação na educação básica: ampliando a discussão. Estudos em Avaliação Educacional, São Paulo, n. 24, p. 137-146, jul./dez. 2001.

DIAS, R.; DELL'ISOLA, R. L. P. Gêneros textuais: teoria e prática de ensino em LE. Campinas: Mercado de Letras, 2012. 
DIONISIO, P. D.; HOFFNAGEL, J. C. (Org.). Gêneros textuais, tipificação e interação. São Paulo: Cortez, 2005.

DIONÍSIO, A. P.; VASCONCELOS, L. J. de. Multimodalidade, gênero textual e leitura. In: BUNZEN, C.; MENDONÇA, M. (Org.). Múltiplas linguagens para o ensino médio. São Paulo: Parábola, 2013. p. 19-42.

FLICK, U. Introdução à pesquisa qualitativa. 3. ed. Porto Alegre: Artmed, 2009.

FULCHER, G.; DAVIDSON, F. Language testing and assessment. London: Routledge, 2007.

HUGHES, A. Testing for language teachers. $2^{\text {nd }}$ ed. Cambridge: Cambridge University Press, 2003.

IEDEMA, R. Multimodality, resemiotization: extending the analysis of discourse as multi-semiotic practice. Sydney, AU: Sage, 2003.

JEWITT, C. The routledge handbook of multimodal analysis. London: Routledge, 2009.

KRESS, G.; van LEEUWEN, T. Introduction: the grammar of visual design. The Semiotic Landscape: language and visual communication. In: KRESS, G.; van LEEUWEN, T. Reading images: the grammar of visual design. London; New York: Routledge, 2006. p. 3-69.

LUDKE, M.; ANDRÉ, M. E. D. A. Pesquisa em Educação: abordagens qualitativas. São Paulo: EPV, 1986.

MARENCO, A. R. L. Questões de leitura multimodal no ensino de lingua inglesa: paralelo entre o livro didático e o exame nacional de ensino médio ENEM. 2014. Dissertação (Mestrado em Letras) - Universidade de Campina Grande, Campina Grande.

MAROUN, C. R. G. O texto multimodal no livro didático de português. In: VIEIRA, J. A. et al. Reflexões sobre a lingua portuguesa: uma abordagem multimodal. Petrópolis: Vozes, 2007. p. 77-107. 
PASSARELLI, L. M. G. Leitura e produção textual. In: ANDRADE, R. J. (Org.). Avaliação de competência na educação básica: um marco referencial para a prática. São Paulo: Moderna, 2011. p. 9-35.

QUEVEDO--CAMARGO, G. Efeito retroativo da avaliação na aprendizagem de línguas estrangeiras: que fenômeno é esse? In: MULIK, K. B. RETORTA, M. S. (Org.). Avaliação no ensino-aprendizagem de línguas estrangeiras: diálogos, pesquisas e reflexões. Campinas: Pontes, 2014. p. 7793.

SCARAMUCCI, M. V. R. Efeito retroativo da avaliação no ensino/ aprendizagem de línguas: o estado da arte. Trab. Ling. Aplic., Campinas, v. 43, n. 2, p. 203--226, jul./dez. 2004.

SCARAMUCCI, M. V. R. Validade e consequências sociais das avaliações em contextos de ensino de línguas. Lingvarvm Arena, v. 2, p. 103-120, 2011.

SCHOFEN, J. R. Gêneros do discurso e parâmetros de avaliação de proficiência em português como lingua estrangeira do exame Celpe-Bras. 2009. Tese (Doutorado em Linguística Aplicada) -Universidade Federal do Rio Grande do Sul, Porto Alegre.

SILVA, R. S. O livro didático de inglês como um gênero discursivo multimodal promotor de letramentos múltiplos. In: HEMAIS, B. J. W. (Org.). Gêneros discursivos e Multimodalidade: desafios, reflexões e propostas no ensino de inglês. São Paulo: Pontes, 2015. p. 35-62.

SCRIBNER, S.; COLE, M. The Psychology of Literacy. Cambridge: Harvard University Press, 1981.

STAKE, R. E. Case studies. In: DENZIN, N. K.; LINCOLN, Y. S. (Org.). Handbook of qualitative research. Thousand Oaks: Sage, 1994. p. 237-261.

VIEIRA, J. A. Novas perspectivas para o texto: uma visão multissemiótica. In: VIEIRA, J. A. et al. Reflexões sobre a língua portuguesa: uma abordagem multimodal. Petrópolis: Vozes, 2007. p. 9-33.

Recebido em: 15/04/2016

Aceito em: 11/08/2016 